\title{
Análise dos atributos relevantes de projetos de desenvolvimento: um estudo do Plano Safra da Agricultura Familiar
}

Lígia M. Mallmann ${ }^{1}$

\section{Resumo}

Este artigo tem o propósito de verificar se o Plano Safra atual, com base no Pronaf, contempla os vinte atributos percebidos como sendo relevantes na implementação de projetos de desenvolvimento inovadores (KLERING, 2003). O levantamento de dados empíricos foi realizado em site de órgão específico, vinculados ao tema em estudo. O planejamento torna-se fundamental, porque a agricultura familiar é considerada pelo Governo um segmento estratégico para o desenvolvimento do país. Além disso, a agricultura familiar é responsável por produzir $70 \%$ dos alimentos consumidos pelos brasileiros, responde por $38 \%$ da renda agropecuária e ocupa quase $75 \%$ da mão de obra do campo (MDA, 2013). $E$, conforme o censo agropecuário (2006), no Rio Grande do Sul, a agricultura familiar ocupa 30,55\% da área territorial do estado. No Plano Safra atual, ficou evidenciado 18 dos 20 atributos percebidos como sendo relevantes na implementação de projetos de desenvolvimento inovadores. Dessa forma, o Plano se consolida, após 17 anos de sua criação, como importante instrumento de política pública, sendo a garantia de crédito aos produtores rurais.

Palavras-chave: Planejamento. Agricultura familiar. Plano Safra.

\begin{abstract}
This article aims to verify if the current Plano Safra, based on Pronaf, contemplates the twenty attributes perceived as being relevant in the implementation innovators development projects (KLERING, 2003). The search of the empirical data in site of specific organ, linked to the topic of this study. The planning becomes critical because the Government considers family farming a strategic sector for the development of the country. In addition, the family farming is responsible for producing $70 \%$ of food consumed by Brazilians, $38 \%$ of agricultural income and occupies almost $75 \%$ of the workforce of the field (MDA, 2013). According to the agricultural census (2006), in Rio Grande do Sul, the family farming occupies $30.55 \%$ of the land area of the state. In the current Plano Safra, evidenced 18 of the 20 attributes perceived as being relevant in the implementation innovators development projects. Thus, the Plan consolidates after 17 years of its creation as an important instrument of public policy and as guarantee credit to farmers.
\end{abstract}

Keywords: Planning. Family farming. Plano Safra.

\footnotetext{
${ }^{1}$ Doutoranda do Programa de Pós-Graduação em Desenvolvimento Regional. Mestrado e Doutorado da Universidade de Santa Cruz do Sul (Unisc). ligiamallmann@bol.com.br.
} 


\section{Introdução}

O território é entendido com seu sentido de uso (RAFFESTIN, 1993), que de acordo com Santos (1994) é sinônimo de espaço geográfico, onde se materializam as relações entre indivíduos e grupos sociais. Nesse sentido, o estudo foi direcionado à agricultura familiar, considerada pelo Governo um segmento estratégico para o desenvolvimento do país. Além de responsável por produzir $70 \%$ dos alimentos consumidos pelos brasileiros, responde por $38 \%$ da renda agropecuária e ocupa quase $75 \%$ da mão de obra do campo (MDA, 2013). E, conforme o censo agropecuário (2006), o Rio Grande do Sul possui 378.546 estabelecimentos atuando na agricultura familiar, ou seja, $85,75 \%$, e ocupa $30,55 \%$ da área territorial do estado. Assim, o Plano Safra tem que ser estruturado e planejado para viabilizar a sua atuação na sociedade.

Lira (1990) coloca que o planejamento não deve ser confundido com a preparação de um documento de estratégia, porque, entre outras razões, tem a seleção, a priorização, a análise de viabilidade e a compatibilidade de visão, que são tarefas contínuas que envolvem todas as sociedades que representam um determinado território. Para Klering (2003), o desenvolvimento das organizações e das sociedades depende da adoção adequada de programas e projetos, métodos ou padrões de trabalho. Padrão tem a conotação de consenso a respeito de procedimento, medida, maneira de pensar, dirigir, controlar e avaliar os objetivos propostos. Os aspectos ou atributos são importantes na implementação dos planos de desenvolvimento. Então, questiona-se: O Plano Safra atual contempla os vinte atributos importantes na implementação?

Este artigo tem por objetivo verificar se o Plano Safra atual, com base no Pronaf, contempla os 20 atributos percebidos como sendo relevantes na implementação de projetos de desenvolvimento inovadores, explicitados por Klering (2003), e contextualizar uma reflexão sobre a importância do Pronaf para a agricultura familiar. O levantamento de dados empíricos foi realizado em site de órgão específico, vinculados ao tema em estudo. Também foi importante explicitar a relevância do planejamento e das políticas públicas para o desenvolvimento econômico e social dos agricultores familiares. 
Com tal propósito, este texto encontra-se assim estruturado: são, primeiramente, apresentados relevantes conceitos relacionados ao planejamento estratégico territorial e suas diversas abordagens na gestão organizacional e na pública; na sequência, aborda-se a relevância das políticas públicas para a agricultura familiar brasileira; após, é caracterizado o Plano Safra como fonte de recursos e política pública para a agricultura familiar e os atributos relevantes de projetos de desenvolvimento (KLERING, 2003). Por fim, faz-se algumas considerações adicionais, bem como uma análise, explicitando a contemplação dos atributos no Plano Safra atual, que julgamos pertinentes ao entendimento deste procedimento.

\section{Planejamento estratégico territorial}

A gestão de espaços geográficos ou territórios, através de ações relacionadas ao planejamento, pode ser explicitada, para fins didáticos, de duas formas distintas: como uma atividade prática e como uma concepção teórica (SIEDENBERG; PASQUALINI, 2010). O território é entendido com seu sentido de uso (RAFFESTIN, 1993), o que, de acordo com Santos (1994), é "sinônimo de espaço geográfico", onde se materializam as relações entre indivíduos e grupos sociais, constituindo-se em locus de exercício de poder, pois supõe assimetrias na posse dos recursos e das estratégias para seu exercício (CASTRO, 2005). A retomada da dimensão territorial, no contexto do planejamento governamental brasileiro, a partir da década de 1990, não é certamente um produto do acaso, mas reflexo de um conjunto de fatores que tiveram como propulsor a imposição do processo de acumulação flexível e globalizado. É vasta a literatura que se ocupa em dissecar os efeitos da globalização sob múltiplos enfoques, dando conta de que o espaço foi abreviado pela mudança dos tempos dos diferentes processos, modificando conceitos, alterando relações econômicas, políticas e flexibilizando os limites territoriais (HARVEY, 1993; SOJA, 1993, SANTOS, 1997 citado por CARGNIN, 2007).

Para Ander-Egg (1995, apud SCHRÖEDER; FINAMORE, 2012), planejamento é a utilização de um conjunto de procedimentos mediante os quais se colocam uma maior racionalidade e organização em um conjunto de atividades e ações articuladas entre si, as quais, previstas antecipadamente, têm o propósito de 
influenciar no curso de determinadas ocorrências, com o fim de alcançar uma situação eleita como desejável, mediante o uso eficiente de meios e recursos escassos ou limitados.

O planejamento estratégico é um processo no qual são identificados e selecionados os grandes objetivos de uma organização. Por meio do planejamento estratégico, é feita a definição de objetos essenciais à entidade organizacional e sua vinculação com os ambientes interno e externo. Segundo Kotler, "planejamento estratégico é definido como o processo gerencial de desenvolver e manter uma adequação razoável entre os objetivos e recursos da empresa e as mudanças e oportunidades de mercado" (KOTLER, 1992, p. 63). Dessa forma, tem-se que o processo de planejamento estratégico é dinâmico, pois objetiva traçar políticas e programas vinculados à missão, valores e negócios da organização, alinhados com o ambiente interno e o externo. Corroborando, Giacomoni (2002, apud AGUIAR, 2012), menciona que planejar significa estabelecer um conjunto de ações a serem realizadas e definir os meios a combinar com vistas à obtenção dos resultados pretendidos.

Para Drucker (2006), planejamento estratégico é o processo contínuo, sistêmico e com o maior conhecimento possível do futuro contido. Requer ainda tomar decisões atuais que envolvem riscos; organizar sistematicamente as atividades necessárias à execução dessas decisões e, através de uma retroalimentação organizada e sistemática, medir o resultado dessas decisões em confronto com as expectativas alimentadas. Ainda, conforme o mesmo autor, planejar é administrar as incertezas na economia, na sociedade e na política. Atualmente devemos mudar o questionamento para realizarmos o planejamento. No planejamento tradicional, nas suposições a respeito do futuro, questionava-se "O que é mais provável que aconteça?" Ao invés disso, o planejamento para a incerteza pergunta: "O que já aconteceu que irá criar o futuro?".

Os dados demográficos são os primeiros a ser olhados. Quase todas as pessoas que estão na força de trabalho, atualmente, permanecerão aí por muito tempo. Houve duas mudanças revolucionárias na força de trabalho: a explosão da educação avançada e a investida das mulheres em carreiras fora de casa. Ambas são fatos consumados. A passagem do centro de gravidade da população dos trabalhadores braçais para a dos trabalhadores de conhecimento e serviços é irrevogável, assim como o envelhecimento tanto da força de trabalho como da 
população. Os homens de negócios ou gestores públicos precisam perguntar: O que esses fatos consumados significam para o nosso negócio, ou para a nossa população? Que oportunidades eles criam? O que ameaçam? E quais as tendências que afetam as organizações e a população? (DRUCKER, 2006).

Nesse sentido, o método de planejamento estratégico situacional - PES torna-se uma ferramenta importante, pois é um conjunto de ideias e técnicas que deveriam conduzir à atuação prática na área do planejamento governamental. Tais ideias são divulgadas como inovadoras e, geralmente, percebidas dessa forma nos locais onde são utilizadas, porque analisam a situação e o que pode ser planejado, a partir da situação em análise. As ideias de Matus poderiam ser consideradas como algo criado a partir de um arranjo de elementos, muitas vezes, já existentes, caracterizando o que J. Friedmann, citado por Gonçalves (2005), denominou de invenção. Assim, o PES representaria uma sistematização de ideias sobre o planejamento que, no geral, são utilizadas em muitas localidades, independentemente do título estratégico ou situacional. Esse esforço de sistematização aproxima o método da ideia de modelo teórico que, caso aplicado, conduziria à modernização da gestão pública (GONÇALVES, 2005).

\section{Etapas do Processo de Planejamento}

Para Lira (1990), o planejamento não deve ser confundido com a preparação de um plano ou documento de estratégia, porque, primeiro, a seleção, priorização, análise de viabilidade e compatibilidade de visão são tarefas contínuas que envolvem todas as sociedades que representam um determinado território; segundo, o documento resultante só irá mostrar os objetivos da transação e os interesses determinados pelos objetivos globais; e, terceiro, a sua realização implicaria na existência de um sistema adequado de incentivos e sanções para a legitimidade do projeto político e da ideologia por trás dele. Para Lira (1990), o planejamento deve seguir dez etapas:

1) O processo de planejamento tem a sua origem e ponto de partida, para 0 projeto político ou arranjos sociais mínimos, a partir do que deve ser especificado e de um modelo a ser seguido; 
2) A partir do resultado do diagnóstico, persegue resultados práticos e identifica a diferença entre a situação atual e a situação do objetivo do planejamento;

3) Definem-se os objetivos a serem alcançados no planejamento, na medida em que as metas são expressas quantitativamente;

4) Realizadas as etapas anteriores e estabelecidas as metas apropriadas, a etapa seguinte é a formulação da estratégia das metas, ou seja, como fazer para alcançá-las. Definir um método que envolve análise da integralidade e análise permanente, a fim de identificar e determinar as ações básicas ou estratégicas a serem introduzidas durante o processo de planeamento, de acordo com uma determinada sequência temporal, sob viabilidade política e viabilidade técnica;

5) As linhas estratégicas de ação que estabelecem a estrutura básica servem para a definição das medidas fundamentais de ordem pública e para 0 desenvolvimento de projetos de investimento. As políticas são os princípios pelos quais um governo utiliza a sua autoridade para orientar o comportamento dos agentes privados e ordernar as agências e funcionários públicos;

6) Formulação dos programas tradicionais, formados por um conjunto de projetos que visam ao mesmo objetivo. Esses programas, que se diferenciam dos projetos de investimentos, significam um conjunto de ações que se destinariam a canalizar recursos para a obtenção de serviços intangíveis na natureza;

7) O plano deve atingir o seu máximo de precisão na formulação e avaliação de programas e projetos. Um projeto é um conjunto de inter-relação e coordenação para alcançar objetivos específicos dentro dos limites de um determinado orçamento e de um determinado período de tempo;

8) $O$ projeto começa a ser executado pelo plano, pela seleção e implementação de políticas;

9) A implementação de programas e projetos são as ações operacionais do processo de investimento para a produção de certos bens e serviços;

10) O plano deverá ser objeto de acompanhamento e de avaliação para analisar até que ponto os seus objetivos estão sendo cumpridos e, 
eventualmente, modificar os instrumentos de políticas, programas e projetos de investimento que estão sendo implementados. O planejamento deve ser de curto, médio e longo prazo.

\section{Políticas públicas para agricultura familiar brasileira}

Os planos, programas e projetos, na administração pública, são formas de organizar toda estratégia governamental para dar cumprimento às políticas públicas que precisam ser implantadas. A estratégia governamental se viabiliza por meio dos instrumentos de planejamento particulares da administração pública, nos quais estão inseridos os programas e projetos, atividades que se tornam ações que a administração pública pretende colocar em prática (AGUILAR, 2012). As políticas públicas são decisões que envolvem questões de ordem pública com abrangência ampla e que visam à satisfação do interesse de uma coletividade. Podem também ser compreendidas como estratégias de atuação pública, estruturadas por meio de um processo decisório composto de variáveis complexas que impactam na realidade (AMABILE, 2012).

Ainda conforme o mesmo autor, as políticas públicas são a concretização da ação governamental. Consideram atores formais e informais em um curso de ação intencional que visa ao alcance de determinado objetivo. Podem ser constituídas de uma função distributiva, redistributiva ou regulatória e inspiram o constante debate sobre a modernização do Estado e, por isso, estão, contemporaneamente, fundando-se mais em estruturas de incentivos e menos em estruturas de gastos governamentais. Portanto, o estudo das políticas públicas deve considerar quatro etapas principais: formulação, execução, monitoramento e avaliação.

Neste sentido, a discussão sobre as políticas públicas para a agricultura familiar vem ganhando legitimidade social no Brasil, passando a ser utilizada com mais frequência nos discursos dos movimentos sociais rurais, pelos órgãos governamentais e por segmentos do pensamento acadêmico, especialmente pelos estudiosos das Ciências Sociais que se ocupam da agricultura e do mundo rural. No transcorrer do processo de formação da economia brasileira, a grande propriedade, baseada no trabalho assalariado, despontou como modelo politicamente reconhecido. Foi ela também que recebeu os maiores estímulos da política agrícola, baseada no crédito rural farto e barato que, a partir da segunda metade dos anos 
1960, procurou modernizá-la e assegurar sua reprodução social. Em contrapartida, o maior segmento da população rural do país, formado pelos produtores que trabalham com suas famílias, ficou à margem dos benefícios oferecidos pelas políticas governamentais de financiamento, comercialização agrícola, assistência técnica, entre outras tantas.

Os estudos sobre agricultura familiar, no contexto brasileiro, surgiram a partir de meados da década de 1990. Nesse período, ocorreram dois eventos que tiveram um impacto social e político muito significativo no meio rural, especialmente na região Centro-Sul. De um lado, no campo político, a adoção da expressão "agricultura familiar" parece ter sido encaminhada como uma nova categoria-síntese pelos movimentos sociais do campo, capitaneados pelo sindicalismo rural ligado à Contag (Confederação Nacional dos Trabalhadores na Agricultura). Em meados dos anos de 1990, assistiu-se a uma verdadeira efervescência desses movimentos, que produziram, inclusive, formas de manifestação política que perduram até a atualidade, como é o caso dos eventos anuais em torno do "Grito da Terra".

Ainda do ponto de vista do mesmo autor, o sindicalismo rural, nesta ocasião, enfrentava diversos desafios, como os impactos da abertura comercial, a falta de crédito agrícola e a queda dos preços dos principais produtos agrícolas de exportação. A inclusão e a afirmação da noção de agricultura familiar mostraram-se capazes de oferecer guarida a um conjunto de categorias sociais, como, por exemplo, assentados, arrendatários, parceiros, integrados a agroindústrias, entre outros, que não mais podiam ser confortavelmente identificados com as noções de pequenos produtores ou, simplesmente, de trabalhadores rurais. A afirmação da agricultura familiar no cenário social e político brasileiro está relacionada à legitimação que o Estado Ihe emprestou ao criar, em 1996, o Programa Nacional de Fortalecimento da Agricultura Familiar (Pronaf). Esse programa foi formulado como resposta às pressões do movimento sindical rural desde o início dos anos de 1990. Surgiu com a finalidade de prover crédito agrícola e apoio institucional às categorias de pequenos produtores rurais, que vinham sendo penalizados pelas políticas públicas, ao longo da década de 1980, e encontravam sérias dificuldades de se manter na atividade rural. Mas a solidificação da agricultura familiar, no cenário político, deu-se por intermédio da Lei Federal n¹1.326, de julho de 2006. 


\section{Agricultura Familiar no Rio Grande do Sul}

Em 2006, pela primeira vez, foi possível obter uma representação abrangente da agricultura familiar brasileira e sul-rio-grandense. A identificação estatística realizada pelo Instituto Brasileiro de Geografia e Estatística (IBGE) - e pelo Ministério do Desenvolvimento Agrário (MDA) - resultou no ajuste das informações levantadas para o Censo Agropecuário de 2006. No entanto, vale apontar que existem discordâncias de parte de alguns cientistas sociais a respeito do procedimento metodológico de classificação da agricultura familiar adotado pelo IBGE. Por exemplo, Navarro (2010, apud GRANDO, 2011), questiona a noção de agricultura familiar oficialmente adotada para a agregação dos dados, considerada por ele inadequada.

Portanto é forte e contínua a presença da agricultura familiar no cenário nacional, caso contrário, não apareceria nas estatísticas divulgadas pelo IBGE. Adquiriu notoriedade estatística na última edição do Censo Agropecuário, norteado pela lei que define o que é agricultura familiar, para fins de formulação das políticas públicas para essa categoria de produtores rurais. Conforme a Lei Federal $\mathrm{n}^{\circ}$ 11.326, de julho de 2006, é considerado agricultor familiar aquele que exerce atividades no meio rural, em uma superfície que não ultrapasse quatro módulos fiscais ${ }^{2}$, com uso predominante de mão de obra familiar e tendo como fonte principal de renda a atividade agrícola.

$\mathrm{Na}$ década de 1990, foi realizado um estudo de identificação da agricultura familiar do Rio Grande do Sul, com base em dados oficiais do IBGE ${ }^{3}$, o qual foi patrocinado pelo MDA e tem por título Agricultura Familiar na Economia - Brasil e Rio Grande do Sul, 1995 a 2003 (2005). A partir de uma metodologia para o cálculo do produto interno bruto - PIB do agronegócio, os estabelecimentos agrícolas definidos como familiares foram dimensionados e avaliados sob o enfoque do agronegócio familiar. O IBGE apresenta os dados estatísticos em dois

\footnotetext{
${ }^{2}$ Unidade de medida agrária expressa em hectares, fixada para cada município, segundo os fatores determinados na Lei ${ }^{\circ} 6746$ de 1979 ; no Rio Grande do Sul, quatro módulos fiscais podem atingir até 160 hectares.

3 Informações levantadas pelo IBGE divulgadas nas publicações: Censo Agropecuário de 1995/96, Pesquisa Agrícola Municipal (PAM), Pesquisa Pecuária Municipal (PPM), Produção da Extração Vegetal e Silvicultura, Pesquisas Trimestrais do Leite e do Abate.
} 
agrupamentos: a "agricultura familiar" e os outros modelos produtivos, denominados de "agricultura não familiar".

Conforme o Censo Agropecuário (2006), no Brasil, o número absoluto dos estabelecimentos familiares representou 4.367.902, e a agricultura não familiar, 807.587 , ou seja, $84,4 \%$ dos estabelecimentos produtivos são da agricultura familiar, disseminados por todo o território brasileiro. Quanto à área de terras, os dados quase se invertem. A área de terras destinadas à agricultura familiar é de 80.250.453 hectares, e para a agricultura não familiar, de 249.690 .940 hectares; neste caso, o percentual da área destinada à agricultura não familiar é de $75,68 \%$, ou seja, $84,4 \%$ dos estabelecimentos familiares utilizam $24,32 \%$ da área de terras.

Ainda, conforme os dados censitários, o Rio Grande do Sul possui 378.546 estabelecimentos atuando na agricultura familiar, e 62.921 na agricultura não familiar, com o percentual de $85,75 \%$ para os estabelecimentos da agricultura familiar. Já a área de terras utilizadas pela agricultura familiar é de 6.171 .622 hectares, e pela agricultura não familiar é de 14.027.867 hectares. A agricultura familiar ocupa 30,55\% da área territorial do estado. O Rio Grande do Sul possui uma distribuição semelhante à do Brasil, porém, com uma vantagem de 6,23\% em hectares de terras ocupados pela agricultura familiar. Segundo o Censo Agropecuário (2006), explicitaremos a ocupação da área de terras usadas pela agricultura familiar (Lei 11.326) no estado gaúcho. Para uma melhor compreensão, segue abaixo a tabela $1 \mathrm{com}$ as informações sobre as formas de ocupação e as áreas de terras utilizadas pela agricultura familiar, no Rio Grande do Sul estado gaúcho, conforme o tipo de utilização, em 2006.

Verifica-se na Tabela 1 que o percentual de área ocupada por lavouras na agricultura familiar é de $44,64 \%$, sendo que $39,84 \%$ são de lavouras temporárias. Conforme o Censo Agropecuário (2006), estas lavouras são ocupadas com as culturas de feijão, mandioca e milho, com a predominância quase absoluta de estabelecimentos familiares. Isso representa a utilização de mão de obra permanente no meio rural e reflete a sua importância econômica. Já a área ocupada por pastagens naturais é de $27,56 \%$, mostrando a importância da pecuária no desempenho das atividades da agricultura familiar gaúcha. 
Tabela 1 - Ocupação das áreas de terras, utilizadas pela agricultura familiar, no RS, conforme o tipo de utilização - 2006

\begin{tabular}{|c|c|c|}
\hline Tipo de utilização da terra & $\begin{array}{l}\text { Área (ha) Agricultura } \\
\text { Familiar (Lei 11.326) }\end{array}$ & $\begin{array}{l}\text { Participação (\%) na } \\
\text { área total do estado }\end{array}$ \\
\hline Total da área no estado gaúcho & 6.171622 & \\
\hline Total da área ocupada por lavouras & 2.755134 & $44,64 \%$ \\
\hline Permanentes & 215227 & $3,49 \%$ \\
\hline Temporárias & 2.459011 & $39,84 \%$ \\
\hline Área plantada com forrageiras para corte & 79243 & $1,28 \%$ \\
\hline Área para cultivo de flores & 1653 & $0,03 \%$ \\
\hline Total da área ocupada por Pastagens & 1.917 .846 & $31,08 \%$ \\
\hline Naturais & 1.700992 & $27,56 \%$ \\
\hline Plantadas, degradadas & 26400 & $0,43 \%$ \\
\hline Plantadas, em boas condições & 190454 & $3,09 \%$ \\
\hline $\begin{array}{l}\text { Total da área ocupada por Matas e/ou } \\
\text { florestas }\end{array}$ & 1.029 .114 & $16,67 \%$ \\
\hline $\begin{array}{l}\text { Naturais, de preservação permanente ou } \\
\text { reserva legal }\end{array}$ & 305940 & $4,96 \%$ \\
\hline $\begin{array}{l}\text { Naturais, exceto de preservação permanente e } \\
\text { em sistemas agroflorestais }\end{array}$ & 526898 & $8,54 \%$ \\
\hline Plantadas com essências florestais & 196276 & $3,18 \%$ \\
\hline $\begin{array}{l}\text { Total da área ocupada por Sistemas } \\
\text { agroflorestais }\end{array}$ & 469.528 & $7,61 \%$ \\
\hline Área cultivada com espécies florestais & 75210 & $1,22 \%$ \\
\hline $\begin{array}{l}\text { Tanques, lagos açudes e/ou área para águas } \\
\text { públicas para exploração da aquicultura }\end{array}$ & 37943 & $0,61 \%$ \\
\hline $\begin{array}{l}\text { Construções, benfeitorias ou caminhos } \\
\text { Terras degradadas }\end{array}$ & $\begin{array}{r}201935 \\
9981\end{array}$ & $\begin{array}{l}3,27 \% \\
0,16 \%\end{array}$ \\
\hline $\begin{array}{l}\text { Terras inaproveitáveis para agricultura ou } \\
\text { Pecuária }\end{array}$ & 144459 & $2,34 \%$ \\
\hline
\end{tabular}

Fonte: IBGE, Censo Agropecuário 2006.

A área ocupada por matas naturais e/ou florestas é de 16,67\% do território utilizado pela agricultura familiar, representando também a sua contribuição com a sustentabilidade ambiental. A agricultura familiar, mesmo ocupando $30,55 \%$ da área territorial do estado, conforme Grando (2011), ocupou 992 mil pessoas em 2006. Esse dado representou 9,4\% da população total estimada para o Rio Grande do Sul. Ainda, conforme a mesma autora, o IBGE aponta o valor global de $R \$ 13,9$ bilhões provenientes de receitas da atividade agropecuária do Estado em 2006. E a receita obtida pelos estabelecimentos familiares foi de $R \$ 6,9$ bilhões. Isso equivale dizer que, a cada $R \$ 100,00$ gerados pela agropecuária estadual, $R \$ 49,60$ advêm da agricultura familiar. Por esta relevância econômica é necessária a implementação de políticas públicas em prol da agricultura familiar, que requer um procedimento de trabalho que leve em conta as diferenças e viabilize a estratificação das atividades dos agricultores familiares. 


\section{Planos Safras da Agricultura Familiar}

A principal política pública atualmente do MDA, após 17 anos de sua implementação, continua em vigor. O Pronaf, que foi criado através do Decreto $n^{\circ}$ 1946, de 28 de junho de 1996, com quatro áreas de atuação básicas: financiamento do custeio e investimento agrícolas; fornecimento de infraestrutura rural; negociação e articulação de políticas públicas e formação de técnicos extensionistas e agricultores. Nesse momento inicial do programa as taxas de juros eram altas (12\% a.a.) e, por isso, houve pouco acesso dos agricultores, principalmente em função do desconhecimento da política por esses agricultores e suas organizações. A exceção foi a região Sul, que devido ao fato dos agricultores estarem mais inseridos nas dinâmicas dos mercados, acabou se sobressaindo (ABRAMOVAY; VEIGA, 1999). A seguir, explicitaremos os planos-safras, que, posteriormente, serão analisados, conforme os atributos relevantes de projetos de desenvolvimento (KLERING, 2003).

Conforme a Cartilha Pronaf (2013/2014), o MDA lança anualmente o Plano Safra da Agricultura Familiar, com vigência de julho a junho do ano seguinte. $O$ conjunto de políticas públicas qualifica e articula os instrumentos construídos e conquistados pelo setor que produz a maior parte dos alimentos consumidos pelos brasileiros. As medidas foram elaboradas com grandes objetivos: aumento de renda, inovação e tecnologia e estímulo à produção de alimentos, com proteção da renda. O Pronaf é a principal política pública de crédito oferecida pelo MDA, o qual recebeu o aporte de $R \$ 4,2$ bilhões no ano-safra 2002/2003. Ao longo de dez safras, o programa teve aumento de recursos de mais de $400 \%$. Na safra atual, dispõe de $R \$$ 21 bilhões para as linhas de crédito.

Para o MDA (2013), o conjunto de políticas públicas apresentadas no Plano Safra da agricultura familiar 2012/2013 qualifica e articula os instrumentos construídos e conquistados por este importante setor produtivo do país. As medidas foram elaboradas com foco em dois grandes objetivos: a organização econômica e a sustentabilidade. A agricultura familiar é um segmento estratégico para o desenvolvimento do país. Além de responsável por produzir $70 \%$ dos alimentos consumidos pelos brasileiros, responde por $38 \%$ da renda agropecuária e ocupa quase $75 \%$ da mão de obra do campo. Mas, para que a agricultura familiar avance na produção de alimentos, de forma sustentável, é preciso enfrentar alguns desafios. 
Entre eles, ampliar a oferta de alimentos, em quantidade e qualidade; estimular o uso sustentável dos recursos naturais e a convivência com as mudanças climáticas; promover alternativas para a redução da pobreza; gerar e qualificar as ocupações produtivas no campo e interiorizar o desenvolvimento. A existência de um conjunto de políticas públicas simultâneas e permanentes contribui para a estabilidade econômica e social do país, e permite definir um novo lugar do rural no desenvolvimento nacional. Dessa forma, o governo federal, por meio do MDA, segue fortalecendo este importante agente de desenvolvimento, que é a agricultura familiar.

Ainda, conforme o MDA (2013), o Plano Safra tem os seguintes objetivos:

- estimular o crescimento da economia do país com mais produção e estabilidade;

- gerar efeitos multiplicadores para outros setores da economia;

- aumentar a renda no campo - tendo na agricultura familiar um modelo estratégico de produção para o desenvolvimento do país;

- aperfeiçoar as políticas para melhor convivência com as mudanças climáticas;

- promover a transição dos sistemas de produção, ao introduzir boas práticas ambientais, e valorizar os sistemas de produção sustentáveis;

- estimular novas cadeias produtivas com base em produtos sustentáveis e saudáveis, buscando capturar as oportunidades que os mercados interno e externo estão propiciando; e

- promover a organização econômica, qualificando a participação da agricultura familiar nas cadeias produtivas.

E, como estratégia, possui as seguintes:

- ampliação da capacidade de investimento;

- proteção e melhoria da renda: mudança climática e preço; 
- incremento da produtividade e articulação de políticas públicas: assistência técnica e extensão rural - Ater ${ }^{4}$;

- organização econômica e acesso aos mercados;

- sustentabilidade na agricultura familiar: sistemas produtivos; e

- políticas para a juventude rural.

O Pronaf, porém, é mais do que um instrumento de garantia de crédito aos produtores rurais. É também uma oportunidade para que os agricultores familiares coloquem em prática o seu projeto de desenvolvimento, suas expectativas de renda e de mudança de vida. Atualmente, o Pronaf conta com mais de 3,5 milhões de contratos - de custeio e de investimento. As modalidades disponíveis do Pronaf geram na agricultura familiar suporte de crédito para as atividades produtivas e econômicas que o Programa financia junto aos agricultores. As linhas de créditos disponibilizadas aos agricultores pelo Pronaf são as seguintes:

- Pronaf Custeio: destina-se ao financiamento das atividades agropecuárias e de beneficiamento ou industrialização e comercialização de produção própria ou de terceiros enquadrados no Pronaf.

- Pronaf Investimento (Mais Alimentos): destina-se ao financiamento da implantação, ampliação ou modernização da infraestrutura de produção e serviços, agropecuários ou não agropecuários, no estabelecimento rural ou em áreas comunitárias rurais próximas.

- Pronaf Agroindústria: destina recursos para o financiamento de investimentos, inclusive em infraestrutura, que visam ao beneficiamento, ao processamento e à comercialização da produção agropecuária e não agropecuária, de produtos florestais e do extrativismo, ou de produtos artesanais além da exploração de turismo rural.

- Pronaf Agroecologia: destina recursos para o financiamento de investimentos nos sistemas de produção agroecológicos ou orgânicos, incluindo-se os custos relativos à implantação e manutenção do empreendimento.

\footnotetext{
${ }^{4}$ A Lei 12.188/2010 institui a Política Nacional de Assistência Técnica e Extensão Rural (PNATER) e a Programa Nacional de Assistência Técnica e Extensão Rural na Agricultura Familiar e na Reforma Agrária (Pronater) e define os princípios e os objetivos dos serviços de ATER.
} 
- Pronaf Eco: oferece recursos para o financiamento de investimentos em técnicas que minimizam o impacto da atividade rural ao meio ambiente, bem como permitam ao agricultor melhor convívio com o bioma em que sua propriedade está inserida.

- Pronaf Floresta: concede recursos para investimentos em projetos para sistemas agroflorestais; exploração extrativista ecologicamente sustentável, plano de manejo florestal, recomposição e manutenção de áreas de preservação permanente e reserva legal e recuperação de áreas degradadas.

- Pronaf Semiárido: financia recursos para investimentos em projetos de convivência com o semiárido, focados na sustentabilidade dos agroecossistemas, priorizando infraestrutura hídrica e implantação, ampliação, recuperação ou modernização das demais infraestruturas, inclusive aquelas relacionadas com projetos de produção e serviços agropecuários e não agropecuários, de acordo com a realidade das famílias agricultoras da região Semiárida.

- Pronaf Mulher: oferece crédito para o financiamento de investimentos de propostas da mulher agricultora.

- Pronaf Jovem: financia investimentos de propostas de crédito de jovens agricultores e agricultoras.

- Pronaf Custeio e Comercialização de Agroindústrias Familiares: destina-se aos agricultores e suas cooperativas ou associações para que financiem as necessidades de custeio do beneficiamento e industrialização da produção própria e/ou de terceiros.

- Pronaf Cota-Parte: financia investimentos para a integralização de cotaspartes dos agricultores familiares filiados a cooperativas de produção. ou para aplicação em capital de giro, custeio ou investimento.

- Microcrédito Rural: destina crédito aos agricultores de mais baixa renda, permite o financiamento das atividades agropecuárias e não agropecuárias, podendo os créditos cobrirem qualquer demanda que possa gerar renda para a família atendida. 
Quadro 1: Resumo de crédito do Pronaf 2012/2013

\begin{tabular}{|c|c|c|c|c|}
\hline Linhas e Grupos & Faixa I & \multicolumn{2}{|c|}{ Faixa II } & Faixa III \\
\hline Pronaf Custeio & $\begin{array}{l}\text { Até } R \$ 10 \text { mil - Juros } \\
\text { de } 1,5 \% \text { a.a. }\end{array}$ & \multicolumn{2}{|c|}{$\begin{array}{l}\text { Mais de } \mathrm{R} \$ 10 \text { mil até } \\
\mathrm{R} \$ 20 \text { mil - Juros de } \\
3 \% \text { a.a. }\end{array}$} & $\begin{array}{l}\text { Mais de } R \$ 20 \text { mil até } \\
R \$ 80 \text { mil - Juros de } \\
4 \% \text { a.a. }\end{array}$ \\
\hline $\begin{array}{l}\text { Pronaf Investimento } \\
\text { (Mais Alimentos) }\end{array}$ & $\begin{array}{l}\text { Até } R \$ 10 \text { mil - Juro } \\
\text { de } 1 \% \text { a.a. }\end{array}$ & \multicolumn{3}{|c|}{$\begin{array}{l}\text { Mais de } \mathrm{R} \$ 10 \text { mil até } \mathrm{R} \$ 130 \mathrm{mil}-\text { Juros de } 2 \% \\
\text { a.a. }\end{array}$} \\
\hline Microcrédito Rural & \multicolumn{4}{|c|}{$\begin{array}{l}\text { Investimento: Até } \mathrm{R} \$ 2,5 \text { mil por operação. Juro de } 0,5 \% \text { a.a., Bônus de } \\
\text { adimplência de } 25 \% \text { até os primeiros } \mathrm{R} \$ 7,5 \text { mil. Custeio: nas condições } \\
\text { estabelecidas no Manual do Crédito Rural - MCR 10.4.2. }\end{array}$} \\
\hline Pronaf Agroecologia & $\begin{array}{l}\text { Até } R \$ 10 \text { mil - Juro } \\
\text { de } 1 \% \text { a.a. }\end{array}$ & \multicolumn{3}{|c|}{$\begin{array}{l}\text { Mais de } \mathrm{R} \$ 10 \text { mil até } \mathrm{R} \$ 130 \text { mil, juros de } 2 \% \\
\text { a.a. }\end{array}$} \\
\hline Pronaf Mulher & $\begin{array}{l}\text { Até } R \$ 2,5 \text { mil - Juro } \\
\text { de } 0,5 \% \text { a.a. Para os } \\
\text { grupos } A, A / C \text { e B }\end{array}$ & \multicolumn{3}{|c|}{$\begin{array}{l}\text { Até } R \$ 10 \text { mil, juro de } 1 \% \text { a.a. Mais de } R \$ 10 \\
\text { mil e até } R \$ 130 \text { mil, juros de } 2 \% \text { a.a. Para o } \\
\text { grupo } V\end{array}$} \\
\hline Pronaf ECO & $\begin{array}{l}\text { Até } \mathrm{R} \$ 10 \text { mil - Juro } \\
\text { de } 1 \% \text { a.a. }\end{array}$ & \multicolumn{3}{|c|}{$\begin{array}{l}\text { Mais de } \mathrm{R} \$ 10 \text { mil até } \mathrm{R} \$ 130 \text { mil - Juros de } 2 \% \\
\text { a.a. }\end{array}$} \\
\hline Pronaf ECO Dendê & \multicolumn{4}{|c|}{$\begin{array}{l}\text { Até } R \$ 8 \text { mil/ha; Até } R \$ 10 \text { mil, juro de } 1 \% \text { ao ano - Acima de } R \$ 10 \text { mil } \\
\text { e até } R \$ 80 \text { mil por mutuário, juros de } R \$ 2 \% \text { a.a. }\end{array}$} \\
\hline $\begin{array}{l}\text { Pronaf ECO } \\
\text { Seringueira }\end{array}$ & \multicolumn{4}{|c|}{ Até $\mathrm{R} \$ 15$ mil/ha; Até $\mathrm{R} \$ 80$ mil por mutuário, juros de $\mathrm{R} \$ 2 \%$ a.a. } \\
\hline Pronaf Agroindústria & \multicolumn{2}{|c|}{$\begin{array}{l}\text { Individual até } R \$ 130 \text { mil; } \\
\text { Cooperativas e associações até } R \$ \\
1 \text { milhão, respeitando o limite } \\
\text { individual de até } R \$ 10 \text { mil. Juro de } \\
1 \% \text { a.a }\end{array}$} & \multicolumn{2}{|c|}{$\begin{array}{l}\text { Individual acima de } R \$ 10 \text { mil e } \\
\text { até } R \$ 130 \text { mil; Cooperativas e } \\
\text { associações acima de } R \$ 1 \text { milhão } \\
\text { e até } R \$ 30 \text { milhões, respeitando } \\
\text { o limite individual de até } R \$ 40 \text { mil. } \\
\text { Juros de } 2 \% \text { a.a }\end{array}$} \\
\hline Pronaf Semiárido & \multicolumn{4}{|c|}{ Até $\mathrm{R} \$ 18$ mil, juro de $1 \%$ a.a. } \\
\hline Pronaf Jovem & \multicolumn{4}{|c|}{ Até $\mathrm{R} \$ 15$ mil, juro de $1 \%$ a.a. } \\
\hline Pronaf Floresta & \multicolumn{4}{|c|}{ Até $\mathrm{R} \$ 35$ mil, juro de $1 \%$ a.a. } \\
\hline $\begin{array}{l}\text { Pronaf Custeio e } \\
\text { Comercialização de } \\
\text { Agroindústrias } \\
\text { Familiares }\end{array}$ & \multicolumn{4}{|c|}{$\begin{array}{l}\text { Individual até } R \$ 10 \text { mil; Empreendimento familiar rural - até } R \$ 210 \text { mil } \\
\text { Associações - até } R \$ 4 \text { milhões. Cooperativas até } R \$ 10 \text { milhões e } \\
\text { Cooperativas Centrais } R \$ 30 \text { milhões. Juros de } 4 \% \text { a.a }\end{array}$} \\
\hline Pronaf Cota-Parte & \multirow{2}{*}{\multicolumn{4}{|c|}{$\begin{array}{l}\text { Individual: até } \mathrm{R} \$ 20 \text { mil; Cooperativa - até } \mathrm{R} \$ 20 \text { milhões; Juros } 4 \% \text { a.a. } \\
\text { Até } \mathrm{R} \$ 20 \text { mil, mais } \mathrm{R} \$ 1.5 \text { mil para ATER. Juro 0,5\% a.a. Bônus de } \\
\text { adimplência de } 44,186 \%\end{array}$}} \\
\hline $\begin{array}{l}\text { Pronaf Investimento } \\
\text { para a Reforma } \\
\text { Agrária }\end{array}$ & & & & \\
\hline $\begin{array}{l}\text { Pronaf Custeio para a } \\
\text { Reforma Agrária }\end{array}$ & \multicolumn{4}{|c|}{ Até $\mathrm{R} \$ 5$ mil por operação; até três operações; juros 1,5\% a.a. } \\
\hline
\end{tabular}

Fonte: Adaptado pela pesquisadora com base disponibilizada pelo Ministério do Desenvolvimento Agrário, 2013.

O Quadro 1 explicita as modalidades atuais do Pronaf, que desde a sua implementação, em 1996, passou por diversas mudanças. No seu início, abrangia quatro áreas de atuação básicas: financiamento do custeio e investimento agrícolas; fornecimento de infraestrutura rural; negociação e articulação de políticas públicas e formação de técnicos extensionistas e agricultores. Nesse momento inicial do programa, a taxa de juros era em torno de $12 \%$ a.a. e, atualmente, nas suas 
diversas modalidades, a taxa mais elevada não ultrapassa $4 \%$ ao ano. O Pronaf, hoje, abrange diversas modalidades, por isso, os agricultores devem buscar informações sobre o sistema de financiamento.

\section{Atributos relevantes de projetos de desenvolvimento}

Para Klering (2003), o desenvolvimento das organizações e sociedades depende da adoção adequada de programas e projetos, métodos ou padrões de trabalho. Padrão tem a conotação de consenso a respeito de procedimento, medida, maneira de pensar, dirigir, controlar e avaliar os objetivos. Os aspectos ou atributos são importantes na implementação dos planos de desenvolvimento. A seguir, elencam-se vinte atributos percebidos como sendo relevantes na implementação de projetos de desenvolvimento inovadores (KLERING, 2003).

1) Introdução de mudanças, qualitativas e quantitativas, em relação a práticas anteriores: um projeto deve introduzir novos modos ou modelos de provisão de bens e serviços, ser capaz de mudar hábitos ou costumes de trabalho, desenvolver produtos e serviços, tanto novos, quanto renovar antigos;

2) Melhoria da qualidade de vida do público-alvo: um projeto deve ser capaz de gerar novas fontes de renda, ou melhorar a habitação, saneamento, saúde, educação do público-alvo; aumentar os cuidados com o meioambiente, as relações com as comunidades, a segurança, a liberdade de expressão, a autoestima dos cidadãos;

3) Autossustentabilidade: um projeto deve ser capaz de vir a sustentar-se de forma própria ou autônoma, tendo em vista seu enfoque no desenvolvimento das pessoas e instituições envolvidas, evitando práticas paternalistas;

4) Viabilidade técnica, gerencial, econômica e financeira: um projeto deve ser exequível em termos técnicos, gerenciais, econômicos e financeiros, ou seja, dispor de tecnologia e recursos suficientes e adequados para sua implementação, e proporcionar adequada relação custo-benefício; 
5) Credibilidade pública: um projeto deve merecer das instituições envolvidas na sua implantação suficiente importância e visibilidade interna, e oferecer pronta-resposta a demandas do público-alvo;

6) Accountability: um projeto deve ter suas contas e seu funcionamento apresentados de forma clara, objetiva e transparente aos seus apoiadores e à sociedade em geral, com prestações regulares de contas;

7) Desenvolvimento de tecnologia e responsabilidade na utilização de recursos e oportunidades: um projeto deve melhorar a gestão de recursos sociais, criando novas tecnologias, desenvolvendo novas habilidades de ação, dentro de critérios de ética, correção e justiça;

8) Consolidação e ampliação do diálogo com a sociedade civil: um projeto deve melhorar a comunicação, interação e envolvimento de uma comunidade, em relação a assuntos de seu interesse, criando uma maior "massa crítica" e consciência social, assim como maior responsabilidade pelas coisas públicas;

9) Articulação com diferentes setores sociais: um projeto deve melhorar a comunicação, a interação e o envolvimento entre os diferentes setores e atores sociais: o setor público, o setor privado e o chamado "terceiro setor", em relação a demandas e assuntos de interesse real e potencial da sociedade, criando maior responsabilidade e solidariedade social, formulando e implementando soluções, principalmente via redes de ações;

10)Articulação entre diferentes atores, grupos, coletivos e segmentos sociais: um projeto deve melhorar a comunicação, participação e comprometimento de diferentes atores, grupos de interesse, coletivos e segmentos sociais, em relação a demandas e assuntos de interesse real e potencial da sociedade, criando maior responsabilidade social, engajamento cívico e solidariedade social, via atuação preferencial em redes;

11)Articulação entre governos de mesmo nível: um projeto deve melhorar o entendimento e a busca de soluções conjuntas entre governos de mesmo nível, via formação de parcerias, associações ou redes de atuação conjunta, de grupos de municípios ou grupos de Estados;

12)Articulação entre governos de diferentes níveis: um projeto deve melhorar o entendimento e a busca de soluções conjuntas entre governos de diferentes níveis, via formação de parcerias, para atuação conjunta, em que cada ente 
federativo cumpre determinado papel, como parte de um sistema ou de uma rede, visando alcançar objetivos comuns entre municípios e Estados e a União;

13)Transferibilidade: um projeto deve criar condições e tecnologias transferíveis e aproveitáveis em outras áreas, contextos, administrações e regiões;

14)Ampliação do número de beneficiários: um projeto deve gerar impactos não apenas sobre o público-alvo principal, mas também sobre outros cidadãos e segmentos localizados ao redor, passíveis de serem sensibilizados e beneficiados de forma indireta;

15)Permeabilidade ao público-alvo: um projeto deve aproximar-se do públicoalvo, ser entendível e compreensível, suficientemente simples, informal e coerente com o modo de vida prevalente, para ser facilmente contatado, assimilado e adotado na vida cotidiana dos cidadãos;

16)Simplificação da vida dos cidadãos: um projeto deve facilitar e simplificar o acesso dos cidadãos a bens e serviços públicos e sociais; deve racionalizar ações, visando maior eficácia, sem desconsiderar aspectos de tradições, de afeições e de valores do público-alvo;

17)Inclusão de minorias sociais: um projeto deve estimular a inclusão ou reinclusão de minorias desfavorecidas historicamente na sociedade, privilegiando maior integração e participação social de segmentos étnicos, de gênero, de idade e de classes sociais que foram historicamente desfavorecidos ou prejudicados;

18)Incorporação de tecnologias facilitadoras da ação pública: um projeto deve estimular a introdução de novas tecnologias (como internet, sistemas de acompanhamento informatizado e outros) que facilitem e torne mais eficaz a ação pública, rompendo ou quebrando paradigmas de ação mais antigos e menos eficazes;

19)Fortalecimento do poder de gerenciamento para governos: um projeto deve fortalecer e até devolver capacidade de gerenciamento efetivo ao setor público; ao mesmo tempo em que delega ações, deve fortalecer a capacidade de planejar, definir estratégias amplas e gerais, visando articular melhor as ações de diferentes atores e setores da sociedade; 
20)Enfoque sistêmico: um projeto deve ter enfoque sistêmico, em que as partes desempenham um papel integrativo para o alcance de objetivos comuns; se aceita caminhos ou opções alternativas (ao invés de lineares e únicas); considera-se o sistema focado como contendo partes e, ao mesmo tempo, fazendo parte de um sistema maior; aceitam-se constantes prevenções, reavaliações e reajustes; enfatizam-se mais as perspectivas dinâmicas e integrativas do que as estáticas e pontuais.

\section{Análise e discussão dos Planos-Safras da Agricultura Familiar e os atributos relevantes}

Primeiramente, foi explicitado o Plano Safra com base no Pronaf, divulgado pelo MDA (2013); posteriormente, especificamos os atributos relevantes de projetos de desenvolvimento, conforme KLERING (2003). O Pronaf recebeu o aporte de R\$ 4,2 bilhões no Plano Safra 2002/2003 e na safra atual, e dispõe de $R \$ 21$ bilhões para as linhas de crédito. O Plano Safra 2013/2014 compreende diversos atributos mencionados Klering (2003), entre eles, a introdução de mudanças, qualitativas e quantitativas, em relação a práticas anteriores. O Plano Safra atual teve aumento, em dez anos, em mais de $400 \%$ do valor de recursos disponíveis. E sua taxa inicial, no ano de 1996, era de $12 \%$ a.a. e hoje a taxa anual mais alta não ultrapassa $4 \%$ ao ano. Também diversificou as modalidades de linhas e grupos de crédito, contendo 16 modalidades atualmente. Outro atributo é a melhoria da qualidade de vida do público-alvo. A importância dessa política fica evidenciada na medida em que se reconhece que a agricultura familiar é um segmento estratégico para o desenvolvimento do país. Além de responsável por produzir $70 \%$ dos alimentos consumidos pelos brasileiros, responde por $38 \%$ da renda agropecuária e ocupa quase $75 \%$ da mão de obra do campo (MDA, 2013).

O Pronaf continua sendo a principal política pública ofertada pelo MDA, mesmo dezessete anos após sua criação, mostrando a sua credibilidade pública, para suprir as demandas de seu público-alvo. Conforme o atributo desenvolvimento de tecnologia e responsabilidade na utilização de recursos e oportunidades, fica explícito, nos objetivos do plano safra, que este visa estimular o crescimento da economia do país com mais produção e estabilidade; estimular novas cadeias produtivas com base em produtos sustentáveis e saudáveis, buscando capturar as 
oportunidades que os mercados interno e externo estão propiciando; e promover a organização econômica, qualificando a participação da agricultura familiar nas cadeias produtivas. O atributo consolidação e ampliação do diálogo com a sociedade civil é realizado por diversos órgãos e sindicatos vinculados à agricultura familiar.

A articulação com diferentes setores sociais e entre diferentes atores, grupos, coletivos e segmentos sociais, fica compreendida nas estratégias utilizadas pelo plano safra, ou seja, ampliação da capacidade de investimento; proteção e melhoria da renda: mudança climática e preço; incremento da produtividade e articulação de políticas públicas: assistência técnica e extensão rural - Ater; organização econômica e acesso aos mercados; sustentabilidade na agricultura familiar: sistemas produtivos e políticas para a juventude rural, incentivando a fixação do jovem no meio rural. Outro atributo importante citado por Klering (2003) é a transferibilidade, ou seja, um projeto deve criar condições e tecnologias transferíveis e aproveitáveis em outras áreas, contextos, administrações e regiões. O programa é de nível nacional, com especificações, nos seus grupos e linhas de crédito, para diversas modalidades, demonstrando a atuação direta na contribuição econômica, como aporte fundamental para o desenvolvimento específico das regiões.

\section{Considerações finais}

O território é entendido com seu sentido de uso (RAFFESTIN, 1993), que, de acordo com Santos (1994) é "sinônimo de espaço geográfico", onde se materializam as relações entre indivíduos e grupos sociais. Nesse sentido, o estudo foi direcionado à agricultura familiar, considerada pelo Governo um segmento estratégico para o desenvolvimento do país. Além de responsável por produzir $70 \%$ dos alimentos consumidos pelos brasileiros, responde por $38 \%$ da renda agropecuária e ocupa quase $75 \%$ da mão de obra do campo (MDA, 2013). E, conforme o censo agropecuário (2006), o Rio Grande do Sul possui 378.546 estabelecimentos atuando na agricultura familiar, e 62.921 na agricultura não familiar, com o percentual de $85,75 \%$ para os estabelecimentos da agricultura familiar. Já a área de terras utilizadas pela agricultura familiar é de 6.171.622 hectares, e pela agricultura não familiar é de 14.027.867 hectares. A agricultura 
familiar ocupa $30,55 \%$ da área territorial do estado. Assim, o Plano Safra, tem que ser estruturado e planejado para viabilizar a sua atuação na sociedade. Para AnderEgg (1995), citado por Schröeder e Finamore (2012), planejamento é a consistente utilização de um conjunto de procedimentos mediante os quais se colocam uma maior racionalidade e organização em um conjunto de atividades e ações articuladas entre si, para alcançar um determinado objetivo.

Este estudo objetivou verificar se o Plano Safra atual, com base no Pronaf, contempla os vinte atributos percebidos como sendo relevantes na implementação de projetos de desenvolvimento inovadores. Para Klering (2003), o desenvolvimento das organizações e sociedades depende da adoção adequada de programas e projetos, métodos ou padrões de trabalho. Padrão tem a conotação de consenso a respeito de procedimento, medida, maneira de pensar, dirigir, controlar e avaliar os objetivos. Portanto, dos vinte atributos relevantes na implementação de projetos de desenvolvimento inovadores, ficou evidenciado, no estudo que, no Plano Safra atual, 18 foram contemplados, e somente dois não foram demonstrados. São eles a Autosustentabilidade e a Accountability. Primeiramente, não se conseguiu verificar a origem dos recursos - 21 bilhões - para a atual safra nem o retorno de pagamento dos financiamentos adquiridos pelos agricultores. Também não era esta a intenção do estudo. O outro atributo foi a Accountability, ou seja, um projeto deve ter suas contas e seu funcionamento apresentado de forma clara, objetiva e transparente aos seus apoiadores e à sociedade em geral, com prestações regulares de contas. Isso foi impossível de perceber, pois o Governo não disponibiliza, de forma transparente e de fácil acesso, as suas contas neste programa.

No entanto, no Plano Safra atual, ficou evidenciado 18 dos 20 atributos percebidos como sendo relevantes na implementação de projetos de desenvolvimento inovadores. Dessa forma, o Plano se consolida, após 17 anos de sua criação, como importante instrumento de política pública, sendo a garantia de crédito aos produtores rurais. É também uma oportunidade para que os agricultores familiares coloquem em prática o seu projeto de desenvolvimento, suas expectativas de renda e de mudança de vida, sem sair da área rural, ou seja, fixando o homem no campo. 


\section{Referências}

AGUILAR, Adélia Martins de. Plano - programas - projetos. Barbacena: Eduemg, 2012.

AMABILE, Antônio Eduardo de Noronha. Plano - programas - projetos. In: . Barbacena: Eduemg, 2012

CASTRO, Inácio de E. de. Geografia e Política. Rio de Janeiro, Bertrand Brasil, 2005.

CARGNIN, Antonio Paulo. A dimensão territorial no planejamento governamental brasileiro: avanços e limitações na elaboração dos Planos PlurianuaisTexto elaborado como contribuição ao I Seminário Reforma do Estado e Território: Integração Sul-Americana e Gestão do Território. Porto Alegre, UFRGS/POSGEA, nov. 2007. Disponível em: <www.posgea.ufrgs.br/noticias/Folder.pdf >. Acesso em: 10 set. 2013.

DRUCKER, Peter. Administrando em tempos de grandes mudanças. São Paulo: Pioneira Thomson Learning, 2006.

GONÇALVES. Raquel Garcia. Modelos emergentes de planejamento: elaboração e difusão. Um estudo do Planejamento Estratégico Situacional. Tese (Instituto de Pesquisa e Planejamento Urbano e Regional) - Universidade Federal do Rio de Janeiro, Rio de Janeiro, 2005.

KLERING, Luis Roque. Atributos relevantes de projetos de desenvolvimento. Porto Alegre: PPGA/EA/UFRGS, 2003.

KOTLER, Philip. Administração de marketing: análise, planejamento, implementação e controle. 2. ed. São Paulo: Atlas, 1992.

LIRA, Luis A. La confección de estrategias de desarrollo regional. Porto Alegre: CED/PRED/PUC, 1990.

MINISTÉRIO DO DESENVOLVIMENTO AGRÁRIO - MDA (2013). Políticas para a agricultura familiar. Disponível em:

<http://www.mda.gov.br/portal/agriculturafamiliar>. Acesso em: 22 set. 2013.

PRONAF. CARTILHA. Plano Safra agricultura familiar (2013/2014). Disponível em: <http://portal.mda.gov.br/portal/saf/arquivos/view/pronaf/arquivos-tecnicos-planosafra-13-14/Condi\%C3\%A7\%C3\%B5es_do_Cr\%C3\%A9dito_2013-2014.pdf > . Acesso em: 10 set. 2013.

RAFFESTIN, Claude. Por uma geografia do poder. São Paulo: Ática, 1993. 
SANTOS, Milton. O retorno do território. In: SANTOS, Milton et al. (Orgs.). Território: globalização e fragmentação. São Paulo: Hucitec/Anpur, 1994. p. 15-28.

SCHRÖEDER, Christine da Silva; FINAMORE, Eduardo Belisário. Planejamento territorial e gestão do conhecimento na governança pública: a experiência do mapa estratégico do corede produção. REDES, Santa Cruz do Sul, v. 17, n. 1, p. 164-181, jan./abr. 2012.

SIEDENBERG, Dieter R.; PASQUALINI, Fernanda. A origem e a trajetória do planejamento regional. In: $\quad(O r g)$. Fundamentos e técnicas de planejamento
estratégico local/regional. Santa Cruz do Sul: Edunisc, 2010. 